\title{
A genome-wide scan to identify signatures of selection in two Iranian indigenous chicken ecotypes
}

Elaheh Rostamzadeh Mahdabi, Ali Esmailizadeh, Ahmad Ayatollahi Mehrgardi and Masood Asadi Fozi

\begin{abstract}
Background: Various regions of the chicken genome have been under natural and artificial selection for thousands of years. The substantial diversity that exits among chickens from different geographic regions provides an excellent opportunity to investigate the genomic regions under selection which, in turn, will increase our knowledge about the mechanisms that underlie chicken diversity and adaptation. Several statistics have been developed to detect genomic regions that are under selection. In this study, we applied approaches based on differences in allele or haplotype frequencies ( $F_{\mathrm{ST}}$ and hapFLK, respectively) between populations, differences in long stretches of consecutive homozygous sequences $(\mathrm{ROH})$, and differences in allele frequencies within populations (composite likelihood ratio $(C L R))$ to identify inter- and intra-populations traces of selection in two Iranian indigenous chicken ecotypes, the Lari fighting chicken and the Khazak or creeper (short-leg) chicken.

Results: Using whole-genome resequencing data of 32 individuals from the two chicken ecotypes, approximately 11.9 million single nucleotide polymorphisms (SNPs) were detected and used in genomic analyses after quality processing. Examination of the distribution of $\mathrm{ROH}$ in the two populations indicated short to long $\mathrm{ROH}$, ranging from 0.3 to $5.4 \mathrm{Mb}$. We found 90 genes that were detected by at least two of the four applied methods. Gene annotation of the detected putative regions under selection revealed candidate genes associated with growth (DCN, MEOX2 and CACNB1), reproduction (ESR1 and CALCR), disease resistance (S1PR1, ALPK1 and MHC-B), behavior pattern (AGMO, GNAO1 and PSEN1), and morphological traits (IHH and NHEJ1).

Conclusions: Our findings show that these two phenotypically different indigenous chicken populations have been under selection for reproduction, immune, behavioral, and morphology traits. The results illustrate that selection can play an important role in shaping signatures of differentiation across the genomic landscape of two chicken populations.
\end{abstract}

\section{Background}

Chickens are raised for different purposes, including meat and egg production, as well as for entertainment, in diverse geographical areas. Several studies have reported the multiple times when and multiple places where the domestication of chicken from the Jungle fowl species

*Correspondence: masadi@uk.ac.ir

Department of Animal Science, Faculty of Agriculture, Shahid Bahonar

University of Kerman, 22 Bahman Blvd, Kerman, Iran occurred. However, most of these studies suggested that domestic chicken originated from the Red Jungle fowl (Gallus gallus) in the south and Southeast Asia [1-4]. Selection pressures affect genome structure over time and leave signatures in specific regions of the genome, such as increased allele frequencies, extensive linkage disequilibrium, homozygous genotypes, and decreased local diversity [5-7]. In addition, forces such as genetic hitchhiking and background selection affect the genomic regions that are near the sites that are under selection [8]. original author(s) and the source, provide a link to the Creative Commons licence, and indicate if changes were made. The images or other third party material in this article are included in the article's Creative Commons licence, unless indicated otherwise in a credit line to the material. If material is not included in the article's Creative Commons licence and your intended use is not permitted by statutory regulation or exceeds the permitted use, you will need to obtain permission directly from the copyright holder. To view a copy of this licence, visit http://creativecommons.org/licenses/by/4.0/. The Creative Commons Public Domain Dedication waiver (http://creativeco mmons.org/publicdomain/zero/1.0/) applies to the data made available in this article, unless otherwise stated in a credit line to the data. 
In order to identify such signatures of selection, different statistical methods have been developed, which are generally categorized into two groups based on whether signatures of selection are investigated within populations (intra-population) or between populations (interpopulation). Among the methods for within-population studies of signatures of selection, some are based on runs of homozygosity ( $\mathrm{ROH}$ ) [9], pooled heterozygosity ( $\mathrm{Hp})$ [10], integrated haplotype scores (iHS) [11], and composite likelihood ratio (CLR) [12]. Methods for betweenpopulation studies are based on the fixation index $\left(F_{\mathrm{ST}}\right)$ [13], cross-population extended haplotype homozygosity (XP-EHH) [7, 14] and hapFLK [15]. Since each of these statistical tests identifies specific patterns of selection in the genome, the joint use of different statistical tests has been suggested to increase the power of detection of signatures of selection along the whole genome $[16,17]$.

To decipher the genetic mechanisms that are involved in domestication and in the phenotypic differentiation of individuals belonging to the same species, detection of signatures of selection using different statistics has been performed in various species, including cattle [18, 19], sheep [20,21], goats [22, 23], and chickens [24-26]. Most of the studies that explored selective footprints in chickens have used the single-site differentiation statistic commonly known as the fixation index, $F_{\mathrm{ST}}$, and have led to the identification of a range of candidates genes that contribute to adaptation to hot climates, reproduction [27], immune response, tolerance to harsh local environments [25], fat deposition, growth, skeletal development, and energy metabolism [28]. However, the $F_{\mathrm{ST}}$ method does not account for the hierarchical structure of populations and assumes that the subpopulations have derived independently from the same ancestral population [15]. To address this deficiency, the HapFLK method, an extension of the FLK statistic based on linkage disequilibrium (LD) [29], was introduced by Fariello et al. [15]. The HapFLK statistic computes signatures of selection by integrating both the hierarchical structure of populations and information on haplotype frequencies, which enhances the power of detection of signatures of selection. Application of the hapFLK approach has led to the detection of signatures of selection related to production and growth traits and to adaptation to extreme environments in noncommercial and commercial chickens [27, 30].

$\mathrm{ROH}$ are contiguous lengths of homozygous segments of the genome where the two identical haplotypes have likely been inherited from a common ancestor. Fleming et al. [25] employed an approach based on assessing the consensus $\mathrm{ROH}$ sequences between two indigenous chicken populations and revealed that different environments, as a driver of selective pressure, may play a role in the genomic divergence of populations. Another analysis of consensus overlapping $\mathrm{ROH}(\mathrm{cROH})$ identified genes that are involved in the immune system and homeostasis maintenance in a paternal broiler line [31]. $\mathrm{ROH}$ and $F_{\mathrm{ST}}$ mapping in African chicken breeds and indigenous ecotypes detected signatures of selection related to adaptation to heat, immunity, calcium ion binding, behavior, etc. [32].

Indigenous chickens are notable for their capacity to adapt to their respective climates and for their disease resistance and it is essential to preserve them as valuable genetic resources. Since Iranian indigenous chickens have never been subjected to selection programs for production traits, mapping the genes and quantitative trait loci (QTL) that are associated with such traits would be useful for future breeding programs. However, there is limited knowledge about the genomic regions and genes involved in economic traits of interest and in adaptation to harsh environment conditions [33].

There is a worldwide diversity of domesticated chickens that differ in morphology, physiology, and behavior [10]. Lari and Khazak are two indigenous ecotypes that are generally maintained in rural areas of Iran. Lari is known as a cockfighting bird and is generally distributed in different regions of Iran and has been selected for fighting characteristics by the locals. In the current study, the Lari samples were collected from the Fars province, situated in the Southern part of Iran, where the Lari ecotype is adapted to a hot and semi-dry climate. It is famous for some morphological and behavioral characteristics such as its large body size, pugnacity, high stamina, and aggressive behavior. Its body shape is unique and different from all other indigenous Iranian ecotypes. The standing posture, long neck (average neck length of $17 \mathrm{~cm}$ ), and long legs (on average $16 \mathrm{~cm}$ ) make it look larger. Its mature body weight is about 3 to $4 \mathrm{~kg}$. Lari chicken produce only 65 to 70 eggs per year. The Khazak ecotype lives in southeastern Iran (Zabol Province), where the climate is hot and dry. It is mostly raised for egg production. Its distinctive feature is its short legs (on average $4 \mathrm{~cm}$ ), such that it is known as a creeper chicken in the local language. Its mature body weight is around 1.2 to $1.5 \mathrm{~kg}$. The Khazak ecotype produces 120 to 130 eggs per year [34,35]. Comparison of the body weight and egg production between these two ecotypes indicates that Lari is more like a broiler while Khazak is more like a layer. The aim of this study was to explore the genomic differences between these two indigenous ecotypes by detecting the regions or sites under natural or artificial selection using resequencing data and four statistical approaches, i.e. $F_{\mathrm{ST}}$, $\mathrm{ROH}$, hapFLK, and CLR. 


\section{Methods}

\section{Sampling and genome sequencing}

Thirty-two chickens were sampled from the south and southeastern regions of Iran (15 Lari and 17 Khazak). Each ecotype was sampled in multiple village flocks in order to minimize family structure or high levels of coancestry between individuals. Extraction of genomic DNA from blood collected in EDTA-coated tubes was carried out using the standard phenol-chloroform protocol [36]. Quantity and quality of each DNA sample were evaluated using an ultraviolet spectrophotometer and agarose gel electrophoresis, respectively. Ten $\mu \mathrm{g}$ of genomic DNA were used to construct libraries with a 350-bp insert size according to the Illumina library preparation pipeline and sequenced on the Illumina Hiseq 2000 platform to generate 125 -bp paired-end reads (Illumina Inc., USA). Before analysis, the raw sequences were checked by the FastQC tool [37] and low-quality reads and adaptors were trimmed out using the Trimmomatic software [38], with default parameters.

\section{Sequence alignment and single nucleotide polymorphism calling}

Paired-end reads were aligned to the chicken reference genome (Galgal6.101) using the mem algorithm in the Burrows-Wheeler Aligner (BWA) software [39], the resulting files were sorted using SAMtools [40], and PCR duplicates that were created during the preparation of genomic libraries were marked and removed by Picard tools (http://broadinstitute.github.io/picard/). In order to improve the accuracy of downstream processing steps, local alignment of the sequences around InDels was performed by RealignerTargetCreator and IndelRealigner in the GATK software [41]. To adjust and improve the base quality scores, we applied BaseRecalibrator and PrintReads, and finally, single nucleotide polymorphism (SNP) calling and hard-filtering were performed using "UnifiedGenotyper" and "VariantFiltration" arguments, respectively, in GATK. We removed the SNPs that were located on sex chromosomes and those that were not assigned to a specific linkage group. The multisampling VCF file was converted to Plink format and the Plink 1.9 software [42] was used to remove individuals with $10 \%$ missing genotypes (zero), and SNPs with a Hardy-Weinberg equilibrium test P-value below the $10 \mathrm{e}-6$ threshold (16,143 SNPs), a genotyping rate lower than $90 \%$ $(1,020,648)$ and a minor allele frequency less than $5 \%$ $(4,377,724$ SNPs).

\section{Population structure}

To investigate the genetic structure and differentiation of the target populations, a phylogeny tree was created by the maximum likelihood method using the PHYLIP package in SNPhylo [43]. A principal component analysis (PCA) was implemented on the filtered SNP data using $\mathrm{R}$ functions in the SNPRelate package [44].

\section{Intra-population signatures of selection Composite likelihood ratio (CLR)}

The CLR test detects differences in allele frequencies along a chromosome between a neutral and a selective sweep model, which is able to detect variants that are close to fixation [45]. We performed a genome-wide scan using Sweepfinder2, which implements a likelihoodbased method [46] to calculate the CLR statistic for each site with a 20-kb grid size across the genome in each population. Putative regions under selection were obtained by dividing the genome into windows of $200 \mathrm{~kb}$. Following a previous approach [47], the maximum CLR was applied as the test statistic and the top $1 \%$ regions of the empirical distribution were deemed significant selective sweeps.

\section{Run of homozygosity (ROH)}

Putative genomic regions under selection within each population were detected by the "Runs of homozygosity" function of the Plink software. The parameters were set according to Ceballos et al. [48], such that a minimum number of 50 SNPs was set to determine ROH. To prevent the underestimation of long $\mathrm{ROH}$ regions and also considering genotyping errors, three heterozygous positions and five missing SNPs were allowed per window. The length of the sliding window was set to $300 \mathrm{~kb}$. A minimum density of $1 \mathrm{SNP}$ per $50 \mathrm{~kb}$ was required to consider a $\mathrm{ROH}$ and the proportion of homozygous overlapping windows was set to 0.05 . The parameter homozyg-group in the Plink software was used to identify overlapping $\mathrm{ROH}$ (pools) based on the threshold of an allelic match with $95 \%$ identity. When a homozygous consensus sequence was detected in more than five individuals of each ecotype within the same region of the genome in a pool, it was considered as a putative region under selection and gene annotation and enrichment analysis were performed for the genes located in these regions.

\section{ROH distribution and inbreeding coefficients}

The frequencies and length of $\mathrm{ROH}$ across the genome can differ between individuals. For instance, a longer $\mathrm{ROH}$ implies recent inbreeding, while a shorter $\mathrm{ROH}$ indicates more ancient common ancestors in the pedigree $[48,49]$. We calculated $\mathrm{ROH}$ and inbreeding coefficients for different classes of $\mathrm{ROH}$ length: short ( 0.3 to $1.0 \mathrm{Mb}$ ), medium (1.0 to $1.5 \mathrm{Mb}$ ), and long (>1.5 Mb) per animal using the runs of homozygosity parameter in the 
Plink software and the method defined by McQuillan et al. [9]:

$$
F_{R O H}=\frac{L_{R O H}}{L_{\text {auto }}},
$$

where $L_{R O H}$ is the sum of the genomic lengths covered by $\mathrm{ROH}$ per animal and $L_{\text {auto }}$ is the autosomal genome length covered by SNPs.

\section{Inter-population genetic differentiation Wright's fixation index $\left(F_{\mathrm{ST}}\right)$}

We compared two indigenous chicken populations that were phenotypically different. The $F_{\mathrm{ST}}$ statistic, which is a method based on the differentiation in allele frequencies between populations, was used to identify genomic footprints of selection between the two populations. This approach has been applied in numerous studies to investigate the underlying genomic mechanism of variation between populations $[26,50]$. To calculate the per-site $F_{\mathrm{ST}}$ statistic between the two populations, we used the VCFtools software [51], based on Weir and Cockerham's $F_{\mathrm{ST}}$ estimator [52]. Pairwise $F_{\mathrm{ST}}$ values were estimated in $50-\mathrm{kb}$ sliding windows along each chromosome, with a step size of $25 \mathrm{~kb}$. The degree of genetic divergence and differentiation between populations $\left(F_{\mathrm{ST}}\right)$ ranges from 0 to 1 , where values close to 0 refer to a low genetic differentiation, i.e. the two populations have no genetic differentiation and share many fixed loci and values close to 1 refer to a stabilized difference between populations [53]. In this study, negative $F_{\mathrm{ST}}$ values were set equal to zero because negative values do not have a biological interpretation [54]. We considered the top $1 \%$ of the empirical distribution of mean $F_{\mathrm{ST}}\left(\mathrm{m} F_{\mathrm{ST}}\right)$ values as divergent selection footprints.

\section{hapFLK test}

The hapFLK statistic which is a haplotype-based approach, was calculated according to the methodology described by Fariello et al. [15] using the hapFLK software that is available at https://forge-dga.jouy.inra. fr/projects/hapflk. We used 10 clusters (-K 10) for the fastPHASE cross-validation procedure to obtain haplotype diversity [55]. The hapFLK statistic was assessed as the average across 15 expectation-maximization runs $(-$ nfit $=15)$ to fit the linkage disequilibrium model.

Since hapFLK values for each SNP along the genome approximately follow a normal distribution, to robustly evaluate the normal distribution parameters, hapFLK values were standardized to evaluate the $\mathrm{p}$-value for each SNP using the formula:

$$
h_{a p F L K} a d j=\frac{h a p F L K-M e a n(h a p F L K)}{S D(h a p F L K)},
$$

as implemented in the rlm function of the R MASS package, where Mean (hapFLK) and $S D$ (hapFLK) refer to the mean and the standard deviation of hapFLK values across the genome, respectively. To limit the number of false positives, the false discovery rate (FDR) was estimated using the R Bioconductor qvalue package [56]. SNPs that reached an FDR threshold of $1 \%$ were considered significant $(-\log 10($ P-value $)=5.19)$.

\section{Gene set enrichment analysis}

To control and avoid the detection of likely false positives by different methods, we focused on signatures of selection that were identified by at least two of the four approaches and on those that were found in peak points in the hapFLK analysis as putative signatures of selection. The genes located in these regions were determined by the Variant Effect Predictor tool (release 101) [57] and functional annotation of the candidate genes, molecular functions, and biological processes was carried out using the Database for Annotation Visualization and Integrated Discovery (DAVID) [58]. Applying the Fisher exact statistics, a P-value $<0.05$ was considered for the statistical significance of $\mathrm{GO}$ term enrichments.

\section{Overlap of signatures of selection with reported QTL}

In order to examine the overlap of the putative genomic regions under selection with previously known QTL, we downloaded the QTL data from the chicken QTL database (http://www.animalgenome.org/cgi-bin/QTLdb/ GG/index). Then, we used the regioneR [59] package and the given region coordinates (chromosome, start and end) to identify reported QTL that were located in the putative regions under selection. However, because of the limited resolution of the QTL localizations, many overlaps are expected to occur by chance. Thus, we used a permutation test $(n=1000)$ to identify statistically significant associations between putative regions and the QTL regions that were repeatedly sampled by the permutation test.

\section{Results}

\section{Sequence alignment and SNP calling}

After quality control and trimming, $\sim 64$ million reads per individual remained. A high percentage (98.0\%) of the short reads were properly mapped to the chicken reference genome (galgal6). The average sequencing depth 
for the 32 individuals was 7.1 (6.9 for Khazak and 7.3 for Lari). In total, 17,287,526 SNPs were detected from the whole-genome data in the initial SNP calling. After quality control, 11,873,011 SNPs across all individuals were retained. Of those, about 6.5 million SNPs were shared between the two ecotypes, and 2.9 and 2.8 million SNPs were specific to the Lari and Khazak ecotypes, respectively.

\section{Population structure analysis}

Using the 11,873,011 SNPs, a maximum likelihood phylogenic tree was constructed and the evolutionary divergence of populations was visualized. Although there were sub-clusters in each population, the two populations segregated into two distinct clusters (Fig. 1a). Population structure, which was evaluated by principle component analysis based on genetic relationships between individuals, classified the birds into two distinct populations, i.e. Lari and Khazak. The PCA results (Fig. 1b) validated those obtained by the phylogenic tree.

\section{Runs of homozygosity and inbreeding}

In the $\mathrm{ROH}$ analysis, $3362 \mathrm{ROH}$ segments were found, with an average of $105.1 \mathrm{ROH}$ per animal (see Additional file 1: Table S1). The average genomic length covered by $\mathrm{ROH}$ per animal was $50.416 \mathrm{Mb}$ and $74.233 \mathrm{Mb}$ for the Khazak and Lari ecotypes, respectively. Consecutive lengths of homozygous genotypes were observed on all chromosomes, except chromosomes 16, 30, 31, 32, and 33. About $70 \%$ of the $\mathrm{ROH}$ segments were located on macro-chromosomes, while $\mathrm{ROH}$ that were more than $5 \mathrm{Mb}$ long were on chromosome $4(71,896,991-$ $77,295,695 \mathrm{bp}$ and $61,312,016-66,772,831 \mathrm{bp})$. The average $\mathrm{ROH}$ coverage was generally higher for short $\mathrm{ROH}$ segments (i.e. shorter than $1.0 \mathrm{Mb}$ ), with a mean coverage of $45.717 \mathrm{Mb}$ per animal, than for long $\mathrm{ROH}$ segments (i.e. longer than $1.0 \mathrm{Mb}$ ), with a mean coverage of $16.730 \mathrm{Mb}$ per animal (Fig. 2). The number of long $\mathrm{ROH}(>1.0 \mathrm{Mb})$ per animal was smaller than the number of short $\mathrm{ROH}(<1.0 \mathrm{Mb})$ for both ecotypes (Fig. 2a). The average number of $\mathrm{ROH}$ segments per individual was larger for the Lari ecotype (126.0 ROH per individual) than for the Khazak ecotype $(89.5 \mathrm{ROH})$. Consequently, the Lari showed a higher inbreeding coefficient $\left(F_{\mathrm{ROH}}\right)$ than the Khazak ecotype (Fig. 2b). For both ecotypes, the highest genomic inbreeding coefficient was found for the $0.3-1 \mathrm{Mb} \mathrm{ROH}$ category (Fig. 2b).

The values of genome-wide inbreeding coefficients differed between the two ecotypes, with the highest, mean and lowest individual $F_{\mathrm{ROH}}$ values equal to $0.28,0.078$, and 0.049 , respectively, for the Lari ecotype, and 0.125 , 0.056, and 0.015 for the Khazak ecotype.

\section{Intra-population signatures of selection CLR statistic}

We computed the CLR test to detect recent selective sweeps in the Lari and Khazak ecotypes. The distribution of CLR values is illustrated in Fig. 3 and revealed

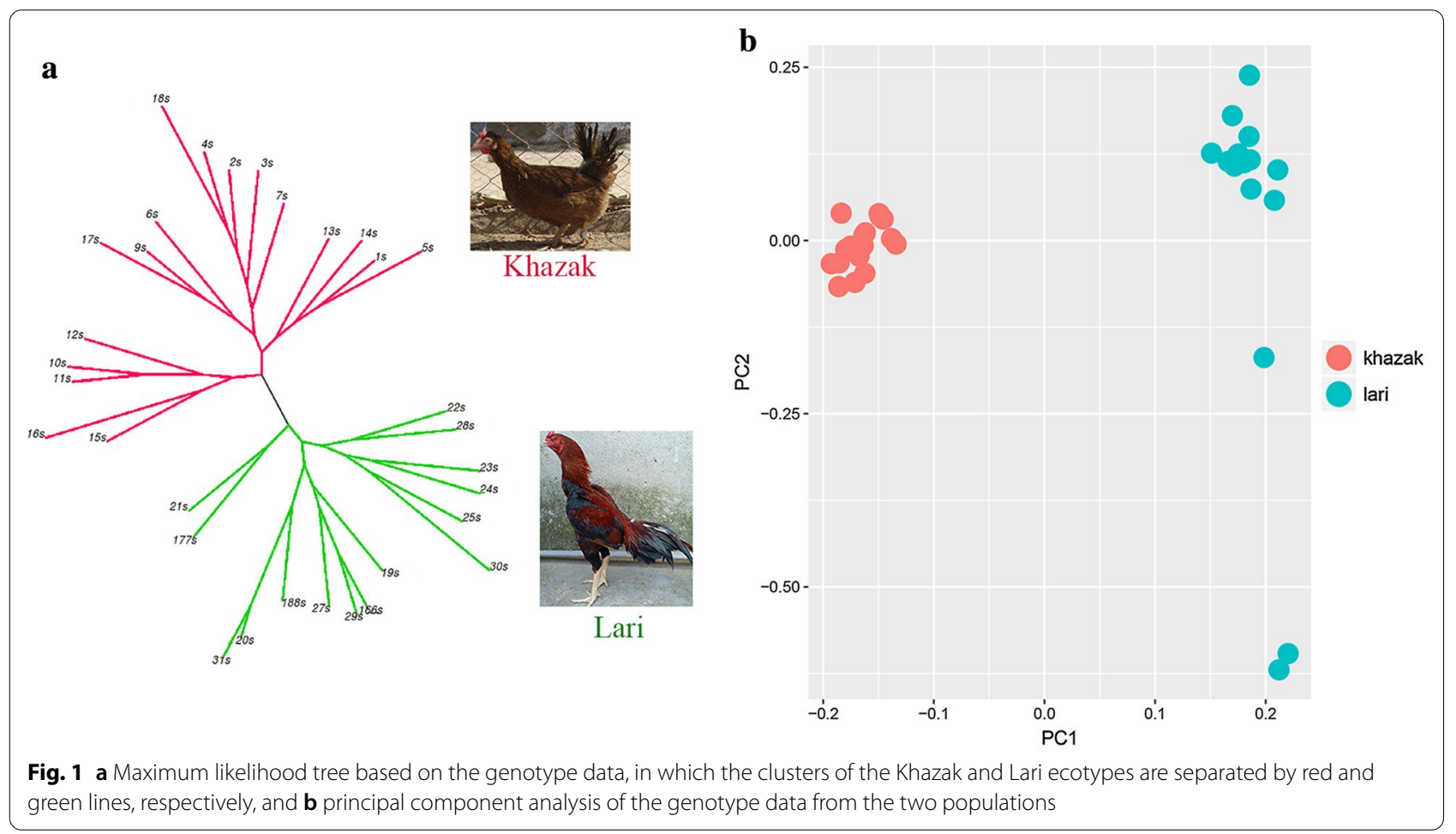



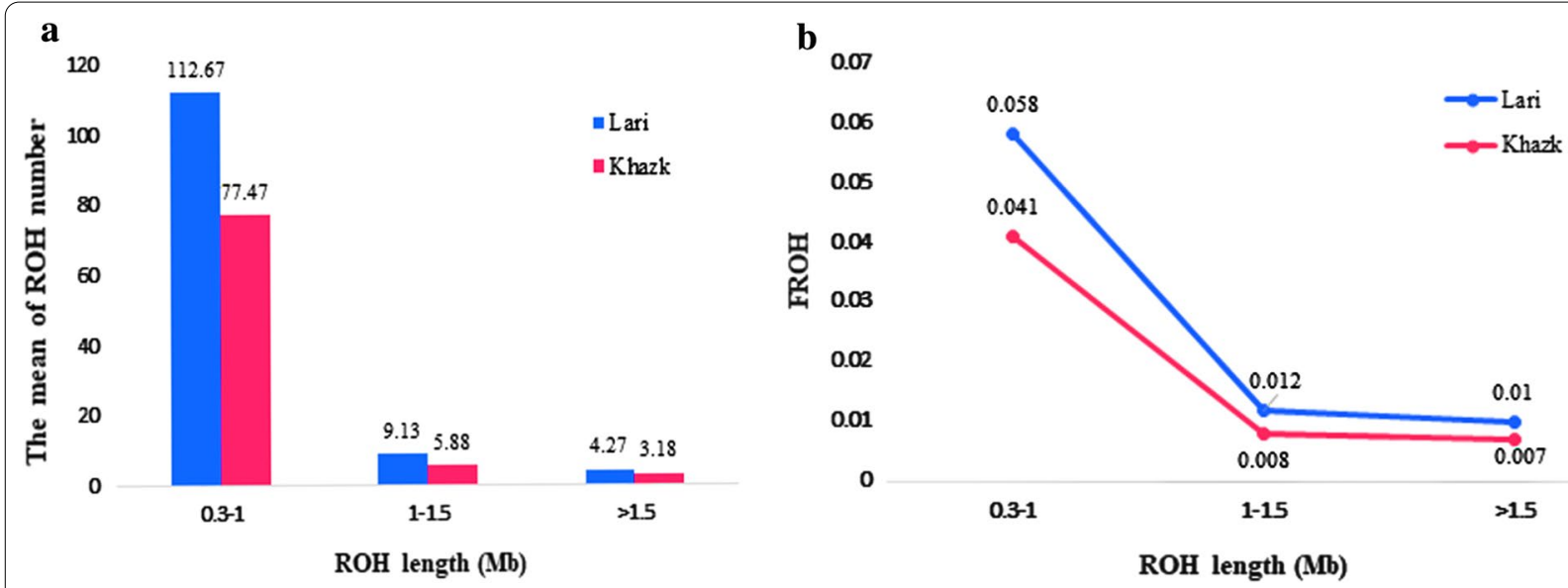

Fig. 2 a The mean of runs of homozygosity number and $\mathbf{b}$ distribution of inbreeding coefficients $\left(F_{\mathrm{ROH}}\right)$ values in the short, medium, and long categories
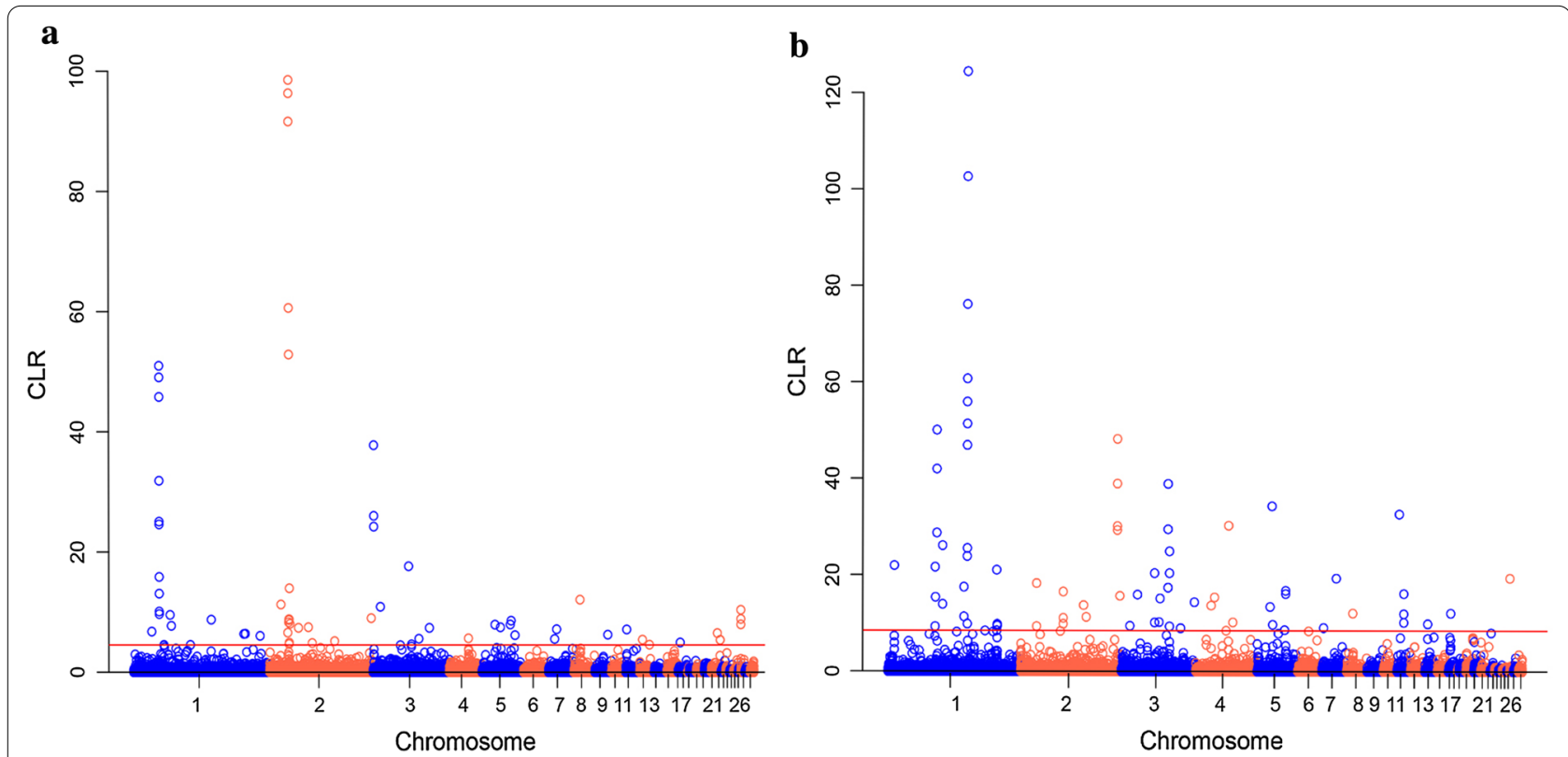

Fig. 3 Distribution of composite likelihood ratio values along the autosomal chromosomes of the Lari (a) and Khazak (b) chickens. The red line corresponds to the top $1 \%$ of the empirical distribution of $C L R$ values

significant genomic positions in the top 1\% CLR scores detected in the Lari $(C L R>4.54)$ and Khazak $(C L R>8.47)$ ecotypes. The most significant CLR value in the Lari ecotype (98.56) was observed on chromosome 2, in a region between 27.6 and $27.8 \mathrm{Mb}$, which harbors the DGKB (diacylglycerol kinase beta) gene (Fig. 3a), while the most significant CLR value in the Khazak ecotype (124.43) was observed on chromosome 1 between 117.6 and $117.8 \mathrm{Mb}$ (Fig. 3b).
We obtained 342 candidate genes for both ecotypes, of which 225 were protein coding genes (see Additional file 2: Table S2). Only seven genes were shared between the two ecotypes. Twenty six and eight genes were shared with the annotated genes in the $F_{\mathrm{ST}}$ and $\mathrm{ROH}$ analyses, respectively (Table 1 ) and (see Additional file 3 : Table S3). Some of the candidate genes identified in the Khazak ecotype have functional relevance to reproduction (ELF3, ESR1, and CALCR), biosynthesis of fatty acid and abdominal fat deposition (ELOVL2 and MAOA), and 


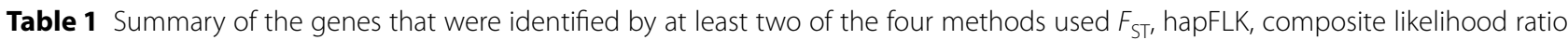
and run of homozygosity

\begin{tabular}{|c|c|c|c|c|c|}
\hline Chr & Gene ID & Gene symbol & Gene start (bp) & Gene end (bp) & Method \\
\hline 1 & ENSGALG00000011274 & $D C N$ & $44,050,178$ & $44,202,174$ & $F_{S T}, \mathrm{ROH}-\mathrm{L}$ \\
\hline 1 & ENSGALG00000012559 & LARGE1 & $52,678,868$ & $52,954,337$ & $F_{S T}, C L R-L$ \\
\hline 1 & ENSGALG00000016288 & ILIRAPLI & $117,527,572$ & $11,8143,733$ & CLR-K, ROH-L-K \\
\hline 2 & ENSGALG00000008591 & CACNB2 & $19,119,896$ & $19,343,839$ & hapFLK, CLR-L \\
\hline 2 & ENSGALG00000009509 & CALCR & $23,060,807$ & $23,197,789$ & $F_{\mathrm{ST}}, \mathrm{CLR}-\mathrm{K}$ \\
\hline 2 & ENSGALG00000010792 & AGMO & $27,838,091$ & $28,021,352$ & $F_{\mathrm{ST}}, \mathrm{CLR}-\mathrm{L}, \mathrm{ROH}-\mathrm{L}$ \\
\hline 2 & ENSGALG00000010794 & MEOX2 & $28,039,372$ & $28,092,164$ & $F_{\mathrm{ST}}, \mathrm{CLR}-\mathrm{L}, \mathrm{ROH}-\mathrm{L}$ \\
\hline 2 & ENSGALG00000010854 & HDAC9 & $29,076,224$ & $29,386,193$ & $F_{S T}, C L R-L$ \\
\hline 2 & ENSGALG00000013817 & SPIRE1 & $97,073,307$ & $97,195,740$ & $F_{\mathrm{ST}}, \mathrm{CLR}-\mathrm{K}$ \\
\hline 3 & ENSGALG00000012973 & ESR1 & $49,053,965$ & $49,241,576$ & $\mathrm{CLR}-\mathrm{K}, \mathrm{ROH}-\mathrm{K}$ \\
\hline 4 & ENSGALG00000012074 & $A L P K 1$ & $57,133,859$ & $57,167,350$ & $F_{\mathrm{ST}}, \mathrm{ROH}-\mathrm{L}$ \\
\hline 5 & ENSGALG00000009320 & PSEN1 & $26,593,233$ & $26,614,911$ & $F_{\mathrm{ST}}, \mathrm{CLR}-\mathrm{L}$ \\
\hline 8 & ENSGALG00000005208 & SIPR1 & $12,067,120$ & $12,071,019$ & $F_{S T}, \mathrm{ROH}-\mathrm{L}$ \\
\hline 20 & ENSGALG00000008010 & PTPN1 & $13,537,599$ & $13,576,469$ & $F_{\mathrm{ST}}, \mathrm{CLR}-\mathrm{K}$ \\
\hline
\end{tabular}

Chr: chromosome number

immune traits (DOCK2, LCP2, PTPN2 and IL1RAPL1), while those identified in the Lari chickens are involved in regulation of energy homeostasis $(A G R P)$, immune $(A P B B 1 I P)$, muscle development (HDAC9), wound healing (MMP13), metabolic regulation and reproduction (TSHR), and behavioral traits (AGMO and PSEN1). In the CLR test, enriched GO terms were revealed for the biological process, cellular components, and molecular functions categories. Functional terms included those involved in epithelial cell proliferation, Golgi organization, and cell differentiation (see Additional file 4: Table S4).

\section{Consensus $\mathrm{ROH}$}

In each ecotype, $\sim 87 \%$ of the consensus $\mathrm{ROH}$ were shared among two to five animals, while 176 consensus $\mathrm{ROH}$ pools that were common to at least five individuals (more than $30 \%$ of the individuals in each ecotype) were identified (110 in the Lari and 65 in the Khazak population) (see Additional file 5: Table S5). The consensus $\mathrm{ROH}$ were located on chromosomes $1,2,3,4,5,7,8,9$, $11,15,17,19$ and 20 in the Khazak and on chromosomes $1,2,3,4,5,6,7,8,11,12,13,14,15$ in the Lari chickens.

Annotation analysis of consensus $\mathrm{ROH}$ revealed 282 protein coding genes (see Additional file 6: Table S6), of which 30 were shared between the two ecotypes (Table 1) and (see Additional file 3: Table S3). One consensus ROH on chromosome 2 ( $347 \mathrm{~kb}: 27,726,057-28,073,095 \mathrm{bp})$, was shared by 11 of the 15 individuals of the Lari ecotype and included the AGMO (alkylglycerol monooxygenase) gene. For the Khazak population, one consensus $\mathrm{ROH}$ was identified on chromosome $8(\sim 84 \mathrm{~kb}$ :
$654,688-738,425 \mathrm{bp})$ that was common to 16 individuals and included long non-coding RNA transcripts.

Seven biological process GO terms were significantly enriched among the genes located in consensus $\mathrm{ROH}$ regions (3 in Lari and 4 in Khazak), of which some contained the terms axonogenesis (GO: 0007409), visual perception (GO: 0007601), blood vessel maturation (GO: 0001955), and response to hypoxia (GO: 0001666) (see Additional file 4: Table S4). Several other genes that were annotated in consensus $\mathrm{ROH}$ were involved in muscle tissue development and regeneration, osteoblast differentiation, breast muscle development, cardiac muscle tissue growth involved in heart morphogenesis, and cardiac muscle contraction. We also observed many genes in the consensus $\mathrm{ROH}$ that have a role in the innate and adaptive immune system, $\mathrm{B}$ cell differentiation, $\mathrm{T}$ cell activation involved in immune response, interleukin-17 production, toll-like receptor 3 signaling pathway, and interleukin-4 production regulation, regulation of the interleukin- 6 biosynthetic process, and inflammatory response. Some of the genes in the consensus $\mathrm{ROH}$ analysis were linked to behavioral traits, including feeding, social, and aggressive behavior, and productive traits such as spermatogenesis, ovarian follicle development, and spermatogenesis (see Additional file 4: Table S4).

\section{Inter-population genetic differentiation $F_{\mathrm{ST}}$ statistic}

Using 25-kb sliding windows, 374 regions with an $\mathrm{m} F_{\mathrm{ST}}$ higher than 0.24 were in the top $1 \%$ of the empirical distribution. These regions were located across most of the chicken chromosomes. The highest $F_{\mathrm{ST}}$ values belonged 


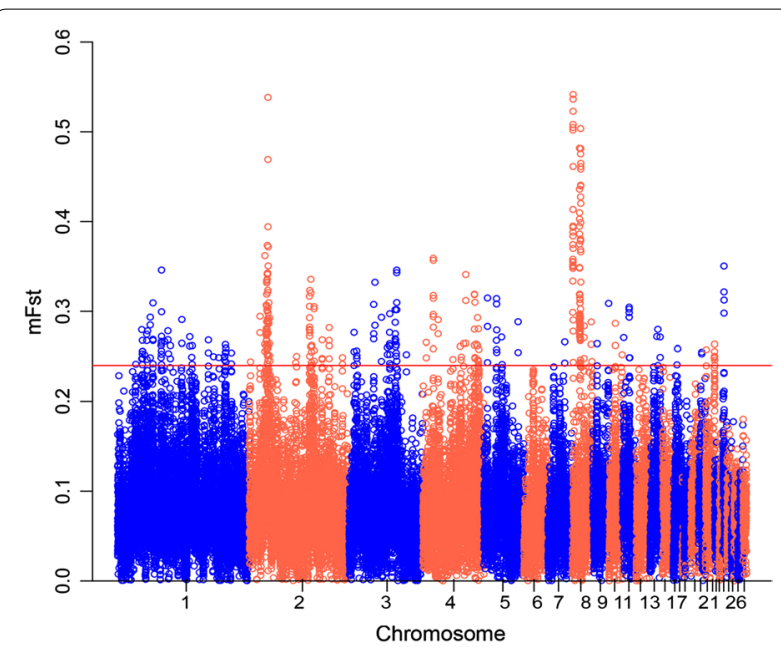

Fig. 4 Distribution of $F_{S T}$ values, showing signatures of differentiation between the Lari and Khazak chickens. The dashed black line corresponds to the top $1 \%$ of the empirical distribution of mean $F_{\text {ST }}$ values

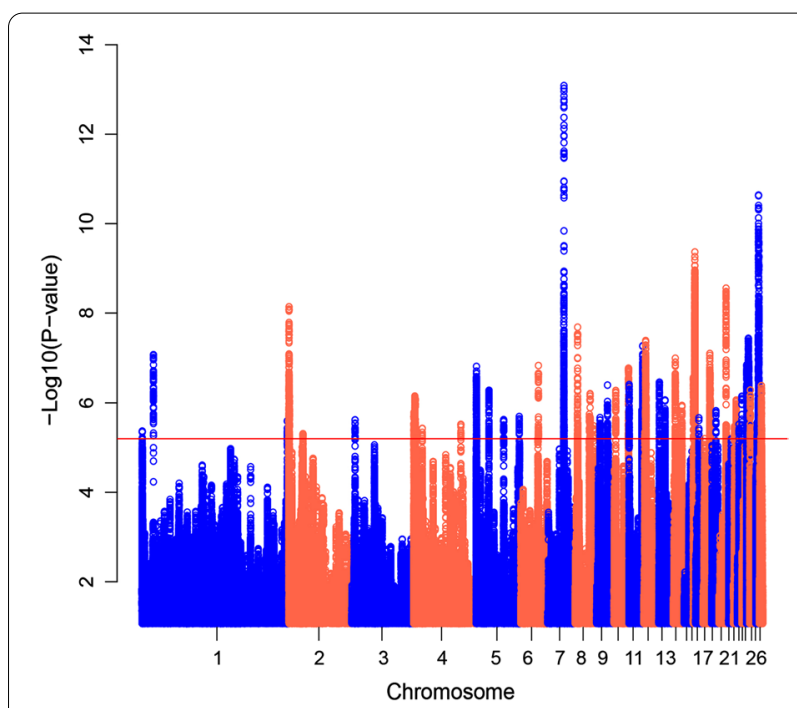

Fig. 5 Distribution of hapFLK values along autosomal chromosomes of the Lari vs. the Khazak chickens. The red line shows the FDR threshold $<0.01$ to an intergenic region on chromosome 8 (875,001$925,000 \mathrm{bp})\left(\mathrm{m} F_{\mathrm{ST}}=0.541\right)$ and a protein-coding region on chromosome $2(27,825,001-27,875,000 \mathrm{bp})$ that spans the $A G M O$ gene $\left(F_{\mathrm{ST}}=0.538\right)$ (Fig. 4). Enrichment analysis of the genes covered significant GO terms related to biological functions, molecular processes, and cellular components related to double-strand break repair, developmental process, vocal learning, transcriptional activator activity, RNA polymerase II core promoter proximal region sequence-specific binding, nucleoplasm and Golgi apparatus (see Additional file 4: Table S4).

In total, 184 protein-coding genes were detected in the putative regions under selection (see Additional file 7: Table S7), among which 54 and 26 genes were common to the annotated genes in the $\mathrm{ROH}$ and CLR analyses, respectively (Table 1 ) and (see Additional file 3 : Table S3). The results derived from the gene annotation analysis showed that multiple genes were involved in the immune system, such as TRIM13 (tripartite motif-containing 13), ALPK1 (alpha kinase 1), S1PR1 (sphingosine-1-phosphate receptor 1), and ITK (IL2-inducible T-cell kinase), which mapped to chromosomes $1,4,8$, and 13, respectively. Furthermore, our results indicate that several genes in the detected regions are associated with growth and reproductive traits, such as DCN (decorin), MEOX2 (mesenchyme homeobox 2), HDAC9 (histone deacetylase 9), SGCZ (sarcoglycan, zeta), LARGE (like-glycosyltransferase), and CITED4 (Cbp/p300-interacting transactivator, with Glu/Asp-rich carboxy-terminal domain, 4) (see Additional file 7: Table S7).

\section{hapFLK statistic}

Results of the hapFLK test are shown in Fig. 5 and Table 2. A threshold of P-value $<6.3 \times 10^{-6}$ was used to declare genomic regions that have been under selection. We observed signatures of selection on all the autosomes except 15,21 , and 24 . The strongest signals were detected on chromosomes 7 (22.05-22.35 Mb), 27 (6.48-7.69 Mb), and $16(2.40-2.75 \mathrm{Mb})$.

In total, 305 protein-coding genes, 14 pseudogenes, 12 miRNA, 10 lncRNA, and one snoRNA were detected in putative regions under selection (see Additional file 8: Table S8). Several functional genes were located within the regions that displayed the strongest signals, including genes involved in the immune system $(B F 1, T A P 1$, $D M B 2$, BLB1, BLB2, TAPBP, BRD2, BLEC1, C4, IKZF3, $D M B 1$, and IL4I1) and in morphological traits such as the creeper (IHH and NHEJ1) and comb traits (MNR2). In addition, important genes relevant to growth and reproductive traits (CACNB1, STAT5B, STAT5A, BCL2L1, GNRHR, FANCA and NTRK1) were detected in several other significant regions (see Additional file 8 : Table S8). The results of the GO enrichment analyses revealed interesting terms related to basic metabolic activities, such as hyaluronan catabolic process, transport, and hyaluronan biosynthetic process (see Additional file 4: Table S4).

\section{QTL overlapping with signatures of selection}

Quantitative trait loci associated with 179 traits that overlapped with detected signatures of selection were 
Table 2 Summary of the regions of putative signatures of selection detected by hapFLK analysis

\begin{tabular}{|c|c|c|c|c|c|}
\hline $\mathrm{Chr}$ & Position (Mb) & $\begin{array}{l}\text { Number of significant } \\
\text { SNPs }\end{array}$ & Peak P-value & Peak Q-value & $\begin{array}{l}\text { Number } \\
\text { of genes }\end{array}$ \\
\hline 1 & $434,470-434,352$ & 5 & $4.27 \times 10^{-6}$ & $8.11 \times 10^{-3}$ & - \\
\hline 1 & $15,481,982-15,485,698$ & 59 & $8.56 \times 10^{-8}$ & $9.62 \times 10^{-4}$ & 2 \\
\hline 1 & $195,604,292-195,605,428$ & 19 & $2.52 \times 10^{-6}$ & $6.11 \times 10^{-3}$ & 3 \\
\hline 2 & $320,222-905,567$ & 318 & $7.26 \times 10^{-9}$ & $2.5 \times 10^{-4}$ & 19 \\
\hline 2 & $19,149,170-19,168,337$ & 9 & $4.90 \times 10^{-6}$ & $8.74 \times 10^{-3}$ & 1 \\
\hline 3 & $4,315,154-4,316,471$ & 28 & $2.40 \times 10^{-6}$ & $5.89 \times 10^{-3}$ & 1 \\
\hline 4 & $592,005-1,129,104$ & 33 & $1.36 \times 10^{-6}$ & $4.73 \times 10^{-3}$ & 2 \\
\hline 4 & $1,793,886-2,540,113$ & 162 & $7.05 \times 10^{-7}$ & $2.98 \times 10^{-3}$ & 6 \\
\hline 4 & $11,848,194-11,848,517$ & 11 & $3.72 \times 10^{-6}$ & $7.53 \times 10^{-3}$ & 1 \\
\hline 4 & $63,734,725-63,735,252$ & 10 & $3.03 \times 10^{-6}$ & $6.72 \times 10^{-3}$ & 1 \\
\hline 5 & $352,470-658,990$ & 128 & $1.56 \times 10^{-7}$ & $1 / 39 \times 10^{-3}$ & 11 \\
\hline 5 & $17,260,400-17,270,064$ & 72 & $5.24 \times 10^{-7}$ & $2.57 \times 10^{-3}$ & 5 \\
\hline 5 & $36,923,176-57,911,202$ & 58 & $2.02 \times 10^{-6}$ & $5.32 \times 10^{-3}$ & 2 \\
\hline 6 & $23,492,639-24,056,037$ & 45 & $1.49 \times 10^{-7}$ & $1.36 \times 10^{-3}$ & 3 \\
\hline 7 & $22,056,870-22,351,378$ & 471 & $9.51 \times 10^{-14}$ & $2.84 \times 10^{-7}$ & 15 \\
\hline 8 & $4,089,299-4,679,692$ & 91 & $2.07 \times 10^{-8}$ & $4.27 \times 10^{-4}$ & 16 \\
\hline 8 & $20,142,893-25,633,392$ & 73 & $6.23 \times 10^{-7}$ & $2.80 \times 10^{-3}$ & 4 \\
\hline 9 & $5,048,355-5,294,874$ & 36 & $2.14 \times 10^{-7}$ & $5.52 \times 10^{-3}$ & 3 \\
\hline 9 & $15,117,357-15,127,879$ & 48 & $4.01 \times 10^{-7}$ & $2.26 \times 10^{-3}$ & 2 \\
\hline 10 & $3,181,235-3,276,403$ & 55 & $5.29 \times 10^{-7}$ & $2.57 \times 10^{-3}$ & 1 \\
\hline 10 & $20,424,930-20,531,639$ & 105 & $1.72 \times 10^{-7}$ & $1.48 \times 10^{-3}$ & 10 \\
\hline 11 & $543,196-552,444$ & 76 & $3.91 \times 10^{-7}$ & $2.24 \times 10^{-3}$ & 4 \\
\hline 11 & $17,670,561-18,929,198$ & 393 & $5.41 \times 10^{-8}$ & $6.79 \times 10^{-4}$ & 23 \\
\hline 12 & $1,844,142-3,584,210$ & 297 & $4.13 \times 10^{-8}$ & $5.99 \times 10^{-4}$ & 21 \\
\hline 13 & $1,681,154-1,716,546$ & 56 & $3.46 \times 10^{-7}$ & $2.13 \times 10^{-3}$ & 2 \\
\hline 13 & $9,215,174-9,262,342$ & 61 & $8.65 \times 10^{-7}$ & $3.29 \times 10^{-3}$ & 4 \\
\hline 14 & $4,527,908-4,542,487$ & 148 & $1.03 \times 10^{-7}$ & $1.01 \times 10^{-3}$ & 2 \\
\hline 14 & $13,457,733-13,466,285$ & 36 & $1.14 \times 10^{-6}$ & $3.83 \times 10^{-3}$ & 4 \\
\hline 16 & $503,770-637,134$ & 55 & $2.77 \times 10^{-7}$ & $1.91 \times 10^{-3}$ & 5 \\
\hline 16 & $2,405,643-2,750,127$ & 1333 & $4.31 \times 10^{-10}$ & $6.35 \times 10^{-5}$ & 38 \\
\hline 17 & $5,162,885-6,250,543$ & 8 & $2.16 \times 10^{-6}$ & $5.56 \times 10^{-3}$ & 5 \\
\hline 18 & $9,029,424-9,781,214$ & 357 & $8.04 \times 10^{-8}$ & $9.20 \times 10^{-4}$ & 21 \\
\hline 19 & $6,101,292-6,102,285$ & 19 & $1.50 \times 10^{-6}$ & $4.52 \times 10^{-3}$ & 1 \\
\hline 20 & $9,895,217-9,899,561$ & 16 & $3.11 \times 10^{-6}$ & $6.83 \times 10^{-3}$ & 3 \\
\hline 20 & $10,004,382-10,590,764$ & 100 & $2.78 \times 10^{-9}$ & $1.64 \times 10^{-4}$ & 5 \\
\hline 22 & $1,480,237-1,486,672$ & 20 & $3.37 \times 10^{-6}$ & $7.14 \times 10^{-3}$ & 1 \\
\hline 22 & $3,734,510-3,835,387$ & 116 & $8.65 \times 10^{-7}$ & $3.29 \times 10^{-3}$ & 8 \\
\hline 22 & $5,266,531-5,268,855$ & 21 & $2.89 \times 10^{-6}$ & $6.56 \times 10^{-3}$ & 3 \\
\hline 23 & $2,341,704-2,342,263$ & 18 & $3.01 \times 10^{-6}$ & $6.71 \times 10^{-3}$ & 1 \\
\hline 23 & $6,082,331-6,085,084$ & 25 & $7.15 \times 10^{-3}$ & $3.00 \times 10^{-3}$ & 2 \\
\hline 25 & $258,310-296,757$ & 77 & $1.44 \times 10^{-7}$ & $1.33 \times 10^{-3}$ & 6 \\
\hline 25 & $1,537,552-1,537,977$ & 18 & $1.61 \times 10^{-6}$ & $4.70 \times 10^{-3}$ & 1 \\
\hline 25 & $2,210,263-3,017,751$ & 531 & $3.38 \times 10^{-8}$ & $5.72 \times 10^{-4}$ & 24 \\
\hline 25 & $3,699,556-3,707,549$ & 51 & $5.03 \times 10^{-7}$ & $2.52 \times 10^{-3}$ & 3 \\
\hline 26 & $1,166,789-1,182,684$ & 56 & $5.17 \times 10^{-7}$ & $2.55 \times 10^{-3}$ & 1 \\
\hline 27 & $5,189,796-5,371,260$ & 43 & $2.47 \times 10^{-6}$ & $6.36 \times 10^{-3}$ & 2 \\
\hline 27 & $6,481,778-7,699,113$ & 871 & $2.31 \times 10^{-11}$ & $8.41 \times 10^{-6}$ & 36 \\
\hline 28 & $2,456,294-3,326,745$ & 99 & $4.13 \times 10^{-7}$ & $2.30 \times 10^{-3}$ & 8 \\
\hline
\end{tabular}


retrieved from the chicken QTL databases (see Additional file 9: Table S9). Analysis of the overlaps between signatures of selection and reported QTL indicated that most of the detected regions contained a QTL (see Additional file 10: Figure S1). Some QTL for traits of economic interest, such as breast muscle weight and percentage, body weight, abdominal fat weight, feed conversion ratio and etc., overlapped significantly with putative regions of signatures of selection (permutation P-value $<0.05$ ). We also found significant overlaps of QTL related to behavioral, morphological, and immune traits (such as feather pecking, drumstick and thigh weight, tibia features, antibody titer to SRBC antigen) with putative regions.

\section{Discussion}

Since the domestication of chickens from the red jungle fowl about 10,000 years ago, evolutionary processes, such as population bottlenecks, migration, inbreeding, and founder effects, have led to a large diversity of chicken populations. A relatively wide range of this diversity is found in the chicken populations of the Iranian plateau and, in this study, we focused on two Iranian native chicken ecotypes, the Lari and Khazak ecotypes. It seems that the Lari ecotype has derived from the Malay breed in the Lar region of the Fars province, Southwest of Iran, in the seventeenth century [35]. According to narrations, the British brought numerous Malay chickens to Iran due to trading between the British and the Iranians on the Persian Gulf shores [35]. The physical similarity of the body shape between the Lari ecotype (long legs and upright posture) and the Malay breed and its dissimilarity with other indigenous ecotypes in Iran support this hypothesis. In contrast, there is no information about the origin of the Khazak ecotype [35, 60].

Through natural selection, local chickens have adapted to harsh environmental conditions, such as heat stress and poor nutrition. In addition, such local chickens are known to represent interesting genetic resources for resistance to local diseases and environments [27, 32]. Muir et al. [61] indicated that pure commercial lines have lost $50 \%$ or more of the genetic diversity (especially rare alleles related to resistance to infectious diseases) that existed in their ancestral breeds and consequently, the poultry industry may have to face unforeseen production challenges such as new virulent diseases. Accordingly, native chicken populations are essential for the poultry breeding programs as sources of rare alleles, to maintain the level of genetic diversity in commercial poultry [61]. In addition, these gene resources could be used as an excellent genetic base in genomic selection and crossbreeding programs to develop meat-type and egg-type chickens in local regions. This could be an important source of income for small-holder farmers who raise such indigenous chickens.

\section{Mapping runs of homozygosity and inbreeding}

Analysis of the distribution of $\mathrm{ROH}$ and of their length and abundance along the genome can provide valuable information about a population's history, genomic inbreeding, and signatures of selection [48, 62, 63]. It has been suggested that the higher resolution of wholegenome sequence data than that of SNP chip data could lead to the identification of $\mathrm{ROH}$ shorter than $1 \mathrm{Mb}$ [26]. In our study, the relatively low coverage of the wholegenome sequence data may have led to the identification of some incorrect $\mathrm{ROH}$ segments. However, Ceballos et al. [48] indicated that SNP chips and low coverage WGS data can achieve equivalent results for $\mathrm{ROH}$ calling. Examination of the distribution of $\mathrm{ROH}$ in the two indigenous chicken populations showed short to long $\mathrm{ROH}$ sizes, ranging from 0.3 to $5.4 \mathrm{Mb}$. $\mathrm{ROH}$ shorter than $1 \mathrm{Mb}$ predominated. Most of the continuous homozygous genotypes were located on macro-chromosomes, while the $\mathrm{ROH}$ on microchromosomes were shorter and less numerous, which confirms previous studies in chickens $[26,32,63]$. It should be noted that recombination rates and nucleotide diversity are much higher for the microchromosomes than for the macrochromosomes [64]. In the future, availability of a precise genetic map of the chicken genome based on whole-genome sequence data would allow the distribution of $\mathrm{ROH}$ by recombination rates to be appropriately scaled to better interpret the difference in the $\mathrm{ROH}$ distribution between the micro- and macrochromosomes.

The average length of the genome covered by $\mathrm{ROH}$ per animal $(62.32 \mathrm{Mb})$ was smaller than the genomic $\mathrm{ROH}$ coverage reported for a commercial broiler line (130.9 Mb on average) [26], which could be the result of lower inbreeding and a wider gene pool in the Iranian indigenous chicken ecotypes than in commercial lines [32]. The frequency of $\mathrm{ROH}$ segments along the genome provides clues about the history and the management of these populations over time $[48,65]$. It has been reported that the larger number of $\mathrm{ROH}$ in broiler lines could be due to the artificial selection pressure on traits of economic interest [26]. Zhang et al. [66] suggested that differences in $F_{\mathrm{ROH}}$ values observed between Chinese indigenous, game, and commercial chicken breeds could be due to differences in selection pressure over time. To test this hypothesis, we applied the $F_{\mathrm{ROH}}$ method to estimate inbreeding within the two populations because it is likely to be the most powerful method to assess inbreeding and it provides more accurate information about the levels of autozygosity than the inbreeding coefficient 
calculated based on pedigree information [31, 67-69]. When the threshold for $\mathrm{ROH}$ size was set to less than $1 \mathrm{Mb}$, both indigenous ecotypes indicated high levels of inbreeding. This likely reflects ancestral relationships and more ancient inbreeding. The length of the $\mathrm{ROH}$ decreases over time due to recombination events, and the presence of short $\mathrm{ROH}$ across the genome indicates more distant shared ancestors [49, 70]. The Lari ecotype showed a higher inbreeding levels for all $\mathrm{ROH}$ categories and generally a higher level of genome-wide inbreeding than the Khazak ecotype. This may be due to the fact that the local farmers select the Lari chickens mainly for fighting and game purposes, while they raise the Khazak ecotype for egg production, which has not been subjected to any breeding program [34].

Identifying positive signatures of selection can provide valuable information about the influence of selection on adaptive, productive, and morphological characteristics. In this study, we applied four procedures, $F_{\mathrm{ST}}$ and hapflk (inter-population), and $\mathrm{ROH}$ and CLR (intra-population), to identify signatures of selection for two phenotypically different chicken ecotypes. Depending on the nature of the information, each of these statistics has its advantages and disadvantages and may capture a specific pattern of selection $[16,17,71]$. The $F_{\mathrm{ST}}$ statistic has been widely applied in various studies, is more powerful for the detection of complex events, but it does not take the hierarchical structure of subpopulations into account; this limitation has been fixed in the hapFLK statistic, which is robust with regard to evolutionary processes, such as bottlenecks and migration, and has the ability to uncover a hard selective sweep, i.e. a new beneficial mutation that rises in frequency and spreads quickly to complete fixation. The CLR statistic can detect selective sweeps that are close to fixation, whereas the short $\mathrm{ROH}$ $(\sim 1 \mathrm{Mb})$ that are detected by consensus $\mathrm{ROH}(\mathrm{cROH})$ analysis mostly arose through selective pressure on identical-by-descent genomic regions from distant ancestors [70]. However, short ROH can also result from other evolutionary processes, such as bottlenecks and genetic drift $[62,68]$. Therefore, considering $\mathrm{ROH}$ regions as signatures of selection should be viewed with caution [72].

\section{Genes related to growth and reproductive traits}

The Lari fighting chickens are characterized by an amazing level of activity. Cockfighting is a form of exercise in which the chicken requires mighty muscle and skeletal structure to run and jump. Thus, we hypothesized that some candidate genes could be connected with muscle growth, hypertrophy, and limb development. Along that line, the two genes DCN (decorin) and MEOX2 (mesenchyme homeobox 2) were good candidates, as both were detected by three of the four applied methods. $D C N$ encodes a connective tissue protein, i.e. a multifunctional proteoglycan that enhances skeletal muscle tissue proliferation and differentiation by interfering with myostatin activity [73]. DCN is also involved in modulating collagen assembly and bone mineralization [74]. Previous studies have reported that $D C N$ expression increases in response to exercise and muscle contraction, which contribute to muscle hypertrophy $[75,76]$. Furthermore, the growth hormone $(\mathrm{GH})$ positively regulates $D C N$ in a genderdependent manner, resulting in greater impact in men than in women [77]. MEOX2 is a homeobox gene and is associated with skeletal muscle tissue and bone development [78]. In mice, genetic deletion of $M E O X 2$ reduces muscle mass and causes a developmental defect in the limb musculature [79]. It has been shown that MEOX2 affects muscle fiber metabolism and muscle size in adult mice [80].

In meat-type chickens, breast muscle is the most valuable carcass component and is one of the most important economic traits. The Lari chickens, with their wide breast and heavy weight (3-4 kg), can be considered as a meattype chicken. In the haplotype-based analysis (hapFLK), we applied a stringent significant threshold to control false positive signals. One of the most striking signatures of selection was detected in a region that contained the CACNB1 (calcium voltage-gated channel auxiliary subunit beta 1) gene on chromosome 27, with a P-value lower than $2.31 \times 10^{-11}$. CACNB1 is known to be associated with body weight in broilers [81] and to play an important role in skeletal muscle growth in mice [82].

Compared with meat-type chickens, the low weight of the Khazak chickens could be an asset because their energy consumption for maintenance will be lower and, thus, most of their feed intake will be dedicated to egg production. Gene annotation of the putative regions identified in the $\mathrm{CROH}$ and CLR analyses identified the ESR1 gene on chromosome 3 as a putative signature of selection for reproductive traits in the Khazak ecotype. In birds, the theca cells are responsible for the synthesis of estrogen in the ovarian follicles. Estrogen regulates the synthesis of egg white and yolk proteins, calcium mobilization, and reproductive behavior, and is necessary for folliculogenesis. The effect of estradiol on folliculogenesis is mediated by the estrogen receptors $\alpha$ and $\beta$, which are encoded by the ESR 1 and ESR2 genes, respectively [83]. In the chicken ovary, expression of the ESR1 gene is higher than that of the ESR2 gene. ESR1 is reported to be associated with ovarian functions, especially during follicular development $[83,84]$, and to be one of the candidate genes for traits related to egg production in chicken and quail $[85,86]$. This gene has also been be associated with reproductive traits in pigs and sheep $[87,88]$. 
Both the $F_{\mathrm{ST}}$ and CLR analyses for the Khazak ecotype revealed another gene that is involved in reproduction traits, CALCR (calcitonin receptor). The calcitonin receptor binds to calcitonin, a polypeptide hormone, and is associated with regulation of follicular maturation in the chicken ovary [89]. In addition, CALCR is known to play a role in calcium homeostasis during pregnancy in mammals to protect the maternal skeleton $[90,91]$.

In the putative regions of signatures of selection, several QTL were previously detected for economically important traits, such as growth, abdominal fat weight, drumstick and thigh muscle weight, egg number, and egg production rate. Since no breeding program has ever been implemented to improve production traits in the Iranian indigenous chickens, the identification of genes and QTL that are associated with these traits in these populations may be important for designing breeding plans in the future.

\section{Genes related to the immune system}

Chickens raised in village regions are under different environmental conditions that can affect their productive performance. Natural selection pressure has led to genetic adaptations in village chickens that allow them to survive in the harsh and diverse environmental conditions [25]. It has been demonstrated that $\mathrm{ROH}$ regions can harbor candidate genes associated with immune responses and adaptation to severe conditions [31, 63]. We identified several genes and previously detected QTL associated with immune traits in the consensus $\mathrm{ROH}$ regions that overlapped with the $F_{\mathrm{ST}}$ windows. For example, the S1PR1 (sphingosine-1-phosphate receptor 1) gene was identified on chromosome 8 and is known to encode a lipid regulator that is involved in processes such as immune response [92] and to contribute to immune response to viral infections, especially influenza infection [93]. Activation of S1PR1 can reduce morbidity and mortality in H5N6-infected chickens by suppressing the induction of cytokines, chemokines, and pattern recognition receptors (PRR) [94]. It has also been shown that the S1PR1 gene plays an essential role in inflammatory responses to infection with the Newcastle disease virus $[95,96]$. Another important gene that was detected is ALPK1 (alpha-kinase 1), which is a member of the group of atypical kinase genes [97]. It contributes to innate immune responses to invasive bacteria and influenza virus $[98,99]$.

In the hapFLK analysis, the strong selective sweep that was detected on chromosome 16 encompasses important genes related to immune traits. Miller and Taylor Jr [100] reported that almost all the genes that are currently mapped to chicken chromosome 16 play a prominent role in immune response. These genes are defined in regional units, of which the best-known region is the major histocompatibility complex- $B(\mathrm{MHC}-B)$. The $\mathrm{MHC}$ is a group of polymorphic genes with a central role in the immune system, particularly in resistance to infectious diseases [101-104]. In our study, this haplotype was identified as a putative region under selection and contains the BF1, BF2, TAP1, DMB2, DMA, BLB1, BLB2, TAPBP, BRD2, BLEC1, C4, IKZF3, BZFP1, CENPA, CYP21A1, LTB4R, HEP21, TRIM7.2, ZNF692, TRIM7.1, TRIM27.1, TRIM27.2, TRIM39.2, TRIM41, TRIM39.1, and GNB2L1 genes. MHC- $B$ haplotypes are important for resistance or susceptibility to infectious diseases such as Marek's disease, Russian sarcoma, and avian leukemia [105, 106].

The population differentiation analyses $\left(F_{\mathrm{ST}}\right.$ and hapFLK) revealed potential candidate genes that are relevant to immune traits. This was expected because the Lari and Khazak ecotypes live in different eco-climates. Moreover, because the Lari chickens are used for entertainment and fighting purposes, they have a higher economic value than the Khazak chickens and thus, they probably receive more healthcare from their owners.

\section{Genes related to morphological and behavioral traits}

The Khazak chickens are characterized by a small body size and, compared to the Lari chickens, the length of their leg is much shorter $(4 \mathrm{~cm}$ vs. $16 \mathrm{~cm}$ ), such that in the local language, they are known as a creeper chicken. Within the identified putative regions of signatures of selection, two genes that are known to influence the creeper trait were detected in the whole-genome scan using the haplotype differentiation analysis. The strongest signal was observed on chromosome 7 between 22.29 and 22.32 Mb, which included 79 SNPs. This region spans two important genes, IHH (Indian hedgehog) and NHEJ1 (non-homologous end-joining factor 1), and has been documented to be the causal genes of the creeper trait in chickens $[107,108]$. The creeper trait is determined by a single autosomal gene in chickens that results in shortened legs [109]. Recently, Kinoshita et al. [107] demonstrated that a $25-\mathrm{kb}$ deletion that harbors the $I H H$ and NHEJ1 genes on chromosome 7 has a significant role in the $C p$ phenotype of Japanese chickens.

Aggressive behavior has been evolutionarily conserved during chicken domestication [110] and is preserved and reinforced in the Lari chicken, which have been bred and trained to fight. Three approaches $\left(F_{\mathrm{ST}}, \mathrm{CLR}\right.$, and $\left.\mathrm{ROH}\right)$ identified the same signature of selection on chromosome 2 , which has the highest $\mathrm{m} F_{\mathrm{ST}}$ value (0.541) and a significant CLR value (8.80). This consensus $\mathrm{ROH}$ region was present in $73.3 \%$ of the Lari population analyzed. This region includes the AGMO (alkylglycerol monooxygenase) gene, which encodes the only enzyme that cleaves 
the $O$-alkyl bond of ether lipids and plays a role in the disabilities and neurodevelopmental disorders in humans $[111,112]$. Luo et al. [113] highlighted the presence of strong selective sweeps for the AGMO gene that are associated with behavioral patterns in the Chinese gamecock chickens. We also detected the GNAO1 gene in a cROH region on chromosome 11 that was present in $47 \%$ of the Lari chickens. It has been shown that the GNAO1 gene is involved in the aggressive behavior of the Xishuangbanna fighting chicken and is under selection in that population $[114,115]$. Another identified candidate gene related to behavioral traits was PSEN1 (presenilin 1), which is located on chromosome 5 and was detected in the $F_{\mathrm{ST}}$ and CLR analyses of the Khazak ecotype. The PSEN1 gene has a role in neuropsychiatric diseases in humans [116] and may contribute to feather pecking behavior [117].

Since each statistical approach is able to detect specific signatures of selection across the genome, it is possible that they do not detect the same region for a given signature of selection [27]. However, Almeida et al. [26] reported that about half of the detected $F_{\mathrm{ST}}$ windows overlapped with the detected cROH across the genome. In our study, we detected several putative regions of signatures of selection and genes that were shared by at least two of the four methods used, but we did not observe overlapping regions between the $F_{\mathrm{ST}}$ and hapFLK approaches because these two methods recognize specific different patterns of signatures of selection. The detection of shared regions under selection by different methods could provide persuasive evidence about the effect of selection on a specific region in the genome, which may be associated with critical functional traits. In addition, the putative regions of signatures of selection that overlap with known QTL can enhance the accuracy of detected signatures of selection [28]. However, to validate these regions, more evidence is required, such as from scanning replicated populations, functional analysis, and positional cloning.

\section{Conclusions}

We implemented four intra and inter-population methods to detect signatures of selection using whole-genome resequencing data in two indigenous chicken ecotypes. Our results revealed several putative footprints of selection that harbor candidate genes associated with disease resistance, growth, reproductive, morphological, and behavioral traits. Although indigenous chicken ecotypes are not always considered for large-scale commercial purposes, they have good potential to survive in harsh environmental conditions. Our findings enhance our understanding of the relationships between phenotype differentiation and genotypes among different breeds.

\section{Supplementary Information}

The online version contains supplementary material available at https://doi. org/10.1186/s12711-021-00664-9.

Additional file 1: Table S1. Summary of the distribution of $\mathrm{ROH}$ lengths along the genome per animal. An excel file containing the number of $\mathrm{ROH}$, total size of genome covered by $\mathrm{ROH}(\mathrm{kb})$ and average of $\mathrm{ROH}$ length $(\mathrm{kb})$ per animal.

Additional file 2: Table S2. List of candidate genes that overlap with regions identified by the CLR method in the Lari and Khazak ecotypes.

Additional file 3: Table S3. List of the genes that were identified simultaneously by at least two of the four applied methods. This table represents the identified common genes shared by at least two of the four methods used, $F_{S T}$, hapFLK, CLR and ROH, (L: Lari ecotype and K: Khazak ecotype).

Additional file 4: Table S4. Summary of GO terms related to biological processes resulting from the analyses of $\mathrm{CROH}$ regions, CLR, $F_{\mathrm{ST}}$ and hapFLK in the Lari and Khazak ecotypes. This table represents gene ontology (GO) terms that are significant (P-value > 0.05), (L: Lari ecotype and K: Khazak ecotype).

Additional file 5: Table S5. List of consensus ROH pools for each ecotype This file contains information about family identification (FID), individual identification (IID), chromosome (CHR), start position (BP1) and end position (BP2), segment size (KB) and number of SNPs in each $\mathrm{ROH}$.

Additional file 6: Table S6. List of candidate genes that overlap with regions identified by the $\mathrm{ROH}$ method in the Lari and Khazak ecotypes.

Additional file 7: Table S7. List of candidate genes that overlap with regions identified by the $F_{\mathrm{ST}}$ method.

Additional file 8: Table S8. List of candidate genes that overlap with regions identified by the hapFLK method.

Additional file 9: Table S9. Overlaps between the reported QTL in the QTL database and the detected candidate regions by $F_{S T}$, hapFLK, CLR and $\mathrm{ROH}$ analysis. This file presents the overlaps between the traits and the position of the known QTL regions in chicken with the position of the identified putative signatures of selection by the four methods.

Additional file 10: Figure S1. Results of the overlap analysis between the regions of signatures of selection (set $A$ ) and known QTL regions in chicken (set B). The $y$-axis shows the number of overlaps between the two datasets. Ain $B$ refers to the region in $A$ encompassed by a region in $B ; B$ in $A$ refers to the region in $B$ encompassed by a region in $A ; A$ left $B$ and Aright $B$ refer to the end and the start of the region of signatures of selection that overlap with the beginning and the end of a region of QTL, respectively.

\section{Acknowledgements}

This work has been supported by the centre for international scientific studies and collaboration (CISSC), Ministry of Science, Research and Technology, Iran (Grant Number: 4000155). We appreciate sampling assistance from animal sample providers in Iran. The authors are grateful to Dr. Hamed Kharrati-Koopaee for his sampling efforts and preparing the DNA samples for sequencing.

\section{Authors' contributions}

$M A$ and $A E$ designed the study. AE prepared the whole genome data. ER analysed and interpreted the data and drafted the manuscript. ER, AE, MA and AAM revised the manuscript. All authors read and approved the final manuscript.

\section{Funding}

This study was funded by the centre for international scientific studies and collaboration (CISSC), Ministry of Science, Research and Technology, Iran (Grant Number: 4000155). 


\section{Availability of data and materials}

The datasets used for the current study are available from the corresponding author upon reasonable request.

\section{Declarations}

\section{Ethics approval and consent to participate}

The whole blood samples applied in the current study were collected according to permission of the animal welfare and ethics committee of Shahid Bahonar University of Kerman (Kerman, Iran).

\section{Consent for publication}

Not applicable.

\section{Competing interests}

The authors declare that they have no competing interests.

Received: 11 January 2021 Accepted: 25 August 2021

Published online: 09 September 2021

\section{References}

1. Sawai H, Kim HL, Kuno K, Suzuki S, Gotoh H, Takada M, et al. The origin and genetic variation of domestic chickens with special reference to junglefowls Gallus g. gallus and G. varius. PLoS One. 2010;5:e10639.

2. Peters J, Lebrasseur O, Best J, Miller H, Fothergill T, Dobney K, et al. Questioning new answers regarding Holocene chicken domestication in China. Proc Natl Acad Sci USA. 2015;112:E2415.

3. Tixier-Boichard M, Bed'hom B, Rognon X. Chicken domestication: from archeology to genomics. C R Biol. 2011:334:197-204.

4. Osman SAM, Yonezawa T, Nishibori M. Origin and genetic diversity of Egyptian native chickens based on complete sequence of mitochondrial DNA D-loop region. Poult Sci. 2016;95:1248-56.

5. Sabeti PC, Schaffner SF, Fry B, Lohmueller J, Varilly P, Shamovsky $\mathrm{O}$, et al. Positive natural selection in the human lineage. Science. 2006;312:1614-20.

6. Nielsen R. Molecular signatures of natural selection. Annu Rev Genet. 2005;39:197-218.

7. Qanbari S, Simianer H. Mapping signatures of positive selection in the genome of livestock. Livest Sci. 2014;166:133-43.

8. Smith JM, Haigh J. The hitch-hiking effect of a favourable gene. Genet Res. 1974;23:23-35.

9. McQuillan R, Leutenegger AL, Abdel-Rahman R, Franklin CS, Pericic M, Barac-Lauc L, et al. Runs of homozygosity in European populations. Am J Hum Genet. 2008:83:359-72.

10. Rubin CJ, Zody MC, Eriksson J, Meadows JR, Sherwood E, Webster MT, et al. Whole-genome resequencing reveals loci under selection during chicken domestication. Nature. 2010;464:587-91.

11. Voight BF, Kudaravalli S, Wen X, Pritchard JK. A map of recent positive selection in the human genome. PLoS Biol. 2006;4:e72.

12. Nielsen R, Williamson S, Kim Y, Hubisz MJ, Clark AG, Bustamante C. Genomic scans for selective sweeps using SNP data. Genome Res. 2005;15:1566-75.

13. Wright $\mathrm{S}$. The genetical structure of species. Ann Eugen. 1951;15:323-54

14. Sabeti PC, Varilly P, Fry B, Lohmueller J, Hostetter E, Cotsapas C, et al. Genome-wide detection and characterization of positive selection in human populations. Nature. 2007:449:913-8.

15. Fariello MI, Boitard S, Naya H, SanCristobal M, Servin B. Detecting signatures of selection through haplotype differentiation among hierarchically structured populations. Genetics. 2013;193:929-41.

16. González-Rodríguez A, Munilla S, Mouresan EF, Cañas-Álvarez JJ, Díaz C, Piedrafita J, et al. On the performance of tests for the detection of signatures of selection: a case study with the Spanish autochthonous beef cattle populations. Genet Sel Evol. 2016:48:81.

17. Vatsiou Al, Bazin E, Gaggiotti OE. Detection of selective sweeps in structured populations: a comparison of recent methods. Mol Ecol. 2016;25:89-103.
18. Yurchenko AA, Daetwyler HD, Yudin N, Schnabel RD, Vander Jagt CJ, Soloshenko V, et al. Scans for signatures of selection in Russian cattle breed genomes reveal new candidate genes for environmental adaptation and acclimation. Sci Rep. 2018;8:12984.

19. Jahuey-Martínez FJ, Parra-Bracamonte GM, Sifuentes-Rincón AM Moreno-Medina VR. Signatures of selection in Charolais beef cattle identified by genome-wide analysis. J Anim Breed Genet. 2019;136:378-89.

20. Wang W, Zhang X, Zhou X, Zhang Y, La Y, Zhang Y, et al. Deep genome resequencing reveals artificial and natural selection for visual deterioration, plateau adaptability and high prolificacy in Chinese domestic sheep. Front Genet. 2019;10:300.

21. Liu Z, Ji Z, Wang G, Chao T, Hou L, Wang J. Genome-wide analysis reveals signatures of selection for important traits in domestic sheep from different ecoregions. BMC Genomics. 2016;17:863.

22. Onzima RB, Upadhyay MR, Doekes HP, Brito LF, Bosse M, Kanis E, et al. Genome-wide characterization of selection signatures and runs of homozygosity in Ugandan goat breeds. Front Genet. 2018;9:318.

23. Bertolini F, Servin B, Talenti A, Rochat E, Kim ES, Oget C, et al. Signatures of selection and environmental adaptation across the goat genome post-domestication. Genet Sel Evol. 2018;50:57.

24. Lawal RA, Al-Atiyat RM, Aljumaah RS, Silva P, Mwacharo JM, Hanotte O. Whole-genome resequencing of red junglefowl and indigenous village chicken reveal new insights on the genome dynamics of the species. Front Genet. 2018:9:264

25. Fleming D, Weigend S, Simianer $\mathrm{H}$, Weigend A, Rothschild M, Schmidt $C$, et al. Genomic comparison of indigenous African and Northern European chickens reveals putative mechanisms of stress tolerance related to environmental selection pressure. G3 (Bethesda). 2017:7:1525-37.

26. Almeida OAC, Moreira GCM, Rezende FM, Boschiero C, de Oliveira PJ, Ibelli $A M G$, et al. Identification of selection signatures involved in performance traits in a paternal broiler line. BMC Genomics. 2019;20:449.

27. Walugembe M, Bertolini F, Dematawewa CMB, Reis MP, Elbeltagy AR, Schmidt CJ, et al. Detection of selection signatures among Brazilian, Sri Lankan, and Egyptian chicken populations under different environmental conditions. Front Genet. 2018:9:737.

28. Boschiero C, Moreira GCM, Gheyas AA, Godoy TF, Gasparin G, Mariani P, et al. Genome-wide characterization of genetic variants and putative regions under selection in meat and egg-type chicken lines. BMC Genomics. 2018;19:83.

29. Bonhomme M, Chevalet C, Servin B, Boitard S, Abdallah J, Blott S, et al. Detecting selection in population trees: the Lewontin and Krakauer test extended. Genetics. 2010;186:241-62.

30. Gholami M, Reimer C, Erbe M, Preisinger R, Weigend A, Weigend S, et al. Genome scan for selection in structured layer chicken populations exploiting linkage disequilibrium information. PLoS One. 2015:10:e0130497.

31. Marchesi JAP, Buzanskas ME, Cantao ME, Ibelli AMG, Peixoto JO, Joaquim $L B$, et al. Relationship of runs of homozygosity with adaptive and production traits in a paternal broiler line. Animal. 2018;12:1126-34

32. Elbeltagy AR, Bertolini F, Fleming DS, Van Goor A, Ashwell CM, Schmidt CJ, et al. Natural selection footprints among African chicken breeds and village ecotypes. Front Genet. 2019;10:376.

33. Mahammi FZ, Gaouar SB, Laloe D, Faugeras R, Tabet-Aoul N, Rognon X, et al. A molecular analysis of the patterns of genetic diversity in local chickens from western Algeria in comparison with commercial lines and wild jungle fowls. J Anim Breed Genet. 2016;133:59-70.

34. Sohrabi SS, Mohammadabadi M, Wu DD, Esmailizadeh A. Detection of breed-specific copy number variations in domestic chicken genome. Genome. 2018:61:7-14.

35. Tavakolian J. An introduction to genetic resources of native farm animals in Iran. Tehran: Animal Science Genetic Research Institute Press; 2000.

36. Iranpur V, Esmailizadeh A, Horriat R, Asadi K, Shiran B, Sorkheh K, et al. Rapid extraction of high quality DNA from whole blood stored at $4^{\circ} \mathrm{C}$ for long period. Shahrekord University. 2002. http://www.protocolonline.org/prot/Protocols/Rapid-Extraction-of-High-Quality-DNA-fromWhole-Blood-Stored-at-4-C-for-Long-Period-4175.html Accessed 24 August 2021 
37. Andrews S. FastQC: a quality control tool for high throughput sequence data. Cambridge: Babraham Institute; 2010.

38. Bolger AM, Lohse M, Usadel B. Trimmomatic: a flexible trimmer for Illumina sequence data. Bioinformatics. 2014;30:2114-20.

39. Li H, Durbin R. Fast and accurate short read alignment with BurrowsWheeler transform. Bioinformatics. 2009;25:1754-60.

40. Li H, Handsaker B, Wysoker A, Fennell T, Ruan J, Homer N, et al. The sequence alignment/map format and SAMtools. Bioinformatics. 2009;25:2078-9.

41. McKenna A, Hanna M, Banks E, Sivachenko A, Cibulskis K, Kernytsky A, et al. The Genome Analysis Toolkit: a MapReduce framework for analyzing next-generation DNA sequencing data. Genome Res. 2010;20:1297-303.

42. Chang CC, Chow CC, Tellier LC, Vattikuti S, Purcell SM, Lee JJ. Secondgeneration PLINK: rising to the challenge of larger and richer datasets. Gigascience. 2015:4:7.

43. Lee TH, Guo H, Wang X, Kim C, Paterson AH. SNPhylo: a pipeline to construct a phylogenetic tree from huge SNP data. BMC Genomics. 2014;15:162.

44. Zheng X, Levine D, Shen J, Gogarten SM, Laurie C, Weir BS. A high-performance computing toolset for relatedness and principal component analysis of SNP data. Bioinformatics. 2012;28:3326-8.

45. Williamson SH, Hubisz MJ, Clark AG, Payseur BA, Bustamante CD, Nielsen R. Localizing recent adaptive evolution in the human genome. PLoS Genet. 2007;3:e90

46. DeGiorgio M, Huber CD, Hubisz MJ, Hellmann I, Nielsen R. SweepFinder2: increased sensitivity, robustness and flexibility. Bioinformatics. 2016;32:1895-7

47. Pickrell JK, Coop G, Novembre J, Kudaravalli S, Li JZ, Absher D, et al. Signals of recent positive selection in a worldwide sample of human populations. Genome Res. 2009;19:826-37.

48. Ceballos FC, Hazelhurst S, Ramsay M. Assessing runs of homozygosity: a comparison of SNP array and whole genome sequence low coverage data. BMC Genomics. 2018;19:106.

49. Curik I, Ferenčaković M, Sölkner J. Inbreeding and runs of homozygosity: a possible solution to an old problem. Livest Sci. 2014;166:26-34

50. Ma Y, Gu L, Yang L, Sun C, Xie S, Fang C, et al. Identifying artificial selection signals in the chicken genome. PLoS One. 2018;13:e0196215.

51. Danecek P, Auton A, Abecasis G, Albers CA, Banks E, DePristo MA, et al. The variant call format and VCFtools. Bioinformatics. 2011;27:2156-8.

52. Weir BS, Cockerham CC. Estimating F-statistics for the analysis of population structure. Evolution. 1984:38:1358-70.

53. Barreiro LB, Laval G, Quach H, Patin E, Quintana-Murci L. Natural selection has driven population differentiation in modern humans. Nat Genet. 2008:40:340-5.

54. Akey JM, Zhang G, Zhang K, Jin L, Shriver MD. Interrogating a highdensity SNP map for signatures of natural selection. Genome Res. 2002;12:1805-14.

55. Scheet $P$, Stephens M. A fast and flexible statistical model for large-scale population genotype data: applications to inferring missing genotypes and haplotypic phase. Am J Hum Genet. 2006;78:629-44.

56. Dabney A, Storey JD, Warnes G. qualue: Q-value estimation for false discovery rate control. R package version. 2010

57. McLaren W, Gil L, Hunt SE, Riat HS, Ritchie GR, Thormann A, et al. The ensembl variant effect predictor. Genome Biol. 2016;17:122.

58. Huang D, Sherman B, Lempicki R. Systematic and integrative analysis of large gene lists using DAVID bioinformatics resources. Nat Protoc. 2009:4:44-57

59. Gel B, Díez-Villanueva A, Serra E, Buschbeck M, Peinado MA, Malinverni $R$. regioneR: an $\mathrm{R} /$ Bioconductor package for the association analysis of genomic regions based on permutation tests. Bioinformatics. 2016:32:289-91.

60. Shahbazi S, Mirhosseini SZ, Romanov MN. Genetic diversity in five Iranian native chicken populations estimated by microsatellite markers. Biochem Genet. 2007;45:63-75.

61. Muir WM, Wong GKS, Zhang Y, Wang J, Groenen MA, Crooijmans RP, et al. Genome-wide assessment of worldwide chicken SNP genetic diversity indicates significant absence of rare alleles in commercial breeds. Proc Natl Acad Sci USA. 2008;105:17312-7.

62. Mastrangelo S, Tolone M, Sardina MT, Sottile G, Sutera AM, Di Gerlando $R$, et al. Genome-wide scan for runs of homozygosity identifies potential candidate genes associated with local adaptation in Valle del Belice sheep. Genet Sel Evol. 2017;49:84.

63. Fleming DS, Koltes JE, Markey AD, Schmidt CJ, Ashwell CM, Rothschild MF, et al. Genomic analysis of Ugandan and Rwandan chicken ecotypes using a 600 k genotyping array. BMC Genomics. 2016;17:407.

64. Axelsson E, Webster MT, Smith NG, Burt DW, Ellegren H. Comparison of the chicken and turkey genomes reveals a higher rate of nucleotide divergence on microchromosomes than macrochromosomes. Genome Res. 2005:15:120-5.

65. Kirin M, McQuillan R, Franklin CS, Campbell H, McKeigue PM, Wilson JF. Genomic runs of homozygosity record population history and consanguinity. PLoS One. 2010;5:e13996.

66. Zhang J, Nie C, Li X, Ning Z, Chen Y, Jia Y, et al. Genome-wide population genetic analysis of commercial, indigenous, game, and wild chickens using 600K SNP microarray data. Front Genet. 2020;1 1:543294.

67. Keller MC, Visscher PM, Goddard ME. Quantification of inbreeding due to distant ancestors and its detection using dense single nucleotide polymorphism data. Genetics. 2011;189:237-49.

68. Ferenčaković M, Hamzić E, Gredler B, Solberg T, Klemetsdal G, Curik I, et al. Estimates of autozygosity derived from runs of homozygosity: empirical evidence from selected cattle populations. J Anim Breed Genet. 2013;130:286-93.

69. Ghoreishifar SM, Moradi-Shahrbabak H, Fallahi MH, Sarghale AJ, MoradiShahrbabak M, Abdollahi-Arpanahi R, et al. Genomic measures of inbreeding coefficients and genome-wide scan for runs of homozygosity islands in Iranian river buffalo Bubalus bubalis. BMC Genet. 2020;21:16.

70. Howrigan DP, Simonson MA, Keller MC. Detecting autozygosity through runs of homozygosity: a comparison of three autozygosity detection algorithms. BMC Genomics. 2011;12:460.

71. Ghoreishifar SM, Eriksson S, Johansson AM, Khansefid M, Moghaddaszadeh-Ahrabi S, Parna N, et al. Signatures of selection reveal candidate genes involved in economic traits and cold acclimation in five Swedish cattle breeds. Genet Sel Evol. 2020;52:52.

72. Purfield DC, McParland S, Wall E, Berry DP. The distribution of runs of homozygosity and selection signatures in six commercial meat sheep breeds. PLoS One. 2017;12:e0176780.

73. Kishioka Y, Thomas M, Wakamatsu J, Hattori A, Sharma M, Kambadur $\mathrm{R}$, et al. Decorin enhances the proliferation and differentiation of myogenic cells through suppressing myostatin activity. J Cell Physiol. 2008;215:856-67.

74. Mochida Y, Parisuthiman D, Pornprasertsuk-Damrongsri S, Atsawasuwan P, Sricholpech M, Boskey AL, et al. Decorin modulates collagen matrix assembly and mineralization. Matrix Biol. 2009;28:44-52.

75. Kanzleiter T, Rath M, Görgens SW, Jensen J, Tangen DS, Kolnes AJ, et al. The myokine decorin is regulated by contraction and involved in muscle hypertrophy. Biochem Biophys Res Commun. 2014;450:1089-94.

76. Heinemeier K, Bjerrum S, Schjerling P, Kjaer M. Expression of extracellular matrix components and related growth factors in human tendon and muscle after acute exercise. Scand J Med Sci Sports. 2013:23:e150-61.

77. Bahl N, Stone G, McLean M, Ho KK, Birzniece V. Decorin, a growth hormone-regulated protein in humans. Eur J Endocrinol. 2018:178:145-52.

78. Mankoo BS, Skuntz S, Harrigan I, Grigorieva E, Candia A, Wright CV, et al. The concerted action of Meox homeobox genes is required upstream of genetic pathways essential for the formation, patterning and differentiation of somites. Development. 2003;130:4655-64.

79. Mankoo BS, Collins NS, Ashby P, Grigorieva E, Pevny LH, Candia A, et al. Mox2 is a component of the genetic hierarchy controlling limb muscle development. Nature. 1999:400:69-73.

80. Otto A, Macharia R, Matsakas A, Valasek P, Mankoo BS, Patel K. A hypoplastic model of skeletal muscle development displaying reduced foetal myoblast cell numbers, increased oxidative myofibres and improved specific tension capacity. Dev Biol. 2010;343:51-62.

81. Tarsani E, Kranis A, Maniatis G, Avendano S, Hager-Theodorides AL, Kominakis A. Discovery and characterization of functional modules associated with body weight in broilers. Sci Rep. 2019;9:125.

82. Chen F, Liu Y, Sugiura Y, Allen PD, Gregg RG, Lin W. Neuromuscular synaptic patterning requires the function of skeletal muscle dihydropyridine receptors. Nat Neurosci. 2011;14:570-7. 
83. Hrabia A, Wilk M, Rząsa J. Expression of $a$ and $\beta$ estrogen receptors in the chicken ovary. Folia Biol (Krakow). 2008;56:187-91.

84. Shen M, Li T, Chen F, Wu P, Wang Y, Chen L, et al. Transcriptomic analysis of circRNAs and mRNAs reveals a complex regulatory network that participate in follicular development in chickens. Front Genet. 2020;11:503.

85. Wu Y, Pan A, Pi J, Pu Y, Du J, Liang Z, et al. SNP analysis reveals estrogen receptor 1 (ESR1) gene variants associated with laying traits in quails. Arch Anim Breed. 2015;58:441-4.

86. Niu X, Tyasi TL, Qin N, Liu D, Zhu H, Chen X, et al. Sequence variations in estrogen receptor 1 and 2 genes and their association with egg production traits in Chinese Dagu chickens. J Vet Med Sci. 2017;79:927-34.

87. Chen M, Wang J, Wang Y, Wu Y, Fu J, Liu J-F. Genome-wide detection of selection signatures in Chinese indigenous Laiwu pigs revealed candidate genes regulating fat deposition in muscle. BMC Genet. 2018;19:31.

88. Ruiz-Larrañaga O, Langa J, Rendo F, Manzano C, Iriondo M, Estonba A. Genomic selection signatures in sheep from the Western Pyrenees. Genet Sel Evol. 2018;50:9.

89. Krzysik-Walker SM, Ocón-Grove OM, Maddineni SB, Hendricks GL 3rd, Ramachandran R. Identification of calcitonin expression in the chicken ovary: influence of follicular maturation and ovarian steroids. Biol Reprod. 2007;77:626-35

90. Lee S, Jeong Y, Simms J, Warner ML, Poyner DR, Chung KY, et al. Calcitonin receptor $\mathrm{N}$-glycosylation enhances peptide hormone affinity by controlling receptor dynamics. J Mol Biol. 2020;432:1996-2014.

91. Woodrow JP, Sharpe CJ, Fudge NJ, Hoff AO, Gagel RF, Kovacs CS. Calcitonin plays a critical role in regulating skeletal mineral metabolism during lactation. Endocrinology. 2006;147:4010-21.

92. Jiang H, Shen SM, Yin J, Zhang PP, Shi Y. Sphingosine 1-phosphate receptor 1 (S1PR1) agonist CYM5442 inhibits expression of intracellular adhesion molecule 1 (ICAM1) in endothelial cells infected with influenza A viruses. PLoS One. 2017;12:e0175188.

93. Tong S, Tian J, Wang H, Huang Z, Yu M, Sun L, et al. H9N2 avian influenza infection altered expression pattern of sphiogosine-1-phosphate receptor 1 in BALB/C mice. Virol J. 2013;10:296.

94. Gao S, Kang Y, Yuan R, Ma H, Xiang B, Wang Z, et al. Immune responses of chickens infected with wild bird-origin H5N6 avian influenza virus. Front Microbiol. 2017;8:1081.

95. Li Y, Xie P, Sun M, Xiang B, Kang Y, Gao P, et al. S1PR1 expression correlates with inflammatory responses to Newcastle disease virus infection. Infect Genet Evol. 2016;37:37-42.

96. Dinarello CA. Immunological and inflammatory functions of the interleukin-1 family. Annu Rev Immunol. 2009:27:519-50.

97. Middelbeek J, Clark K, Venselaar H, Huynen MA, Van Leeuwen FN. The alpha-kinase family: an exceptional branch on the protein kinase tree. Cell Mol Life Sci. 2010;67:875-90.

98. Milivojevic M, Dangeard AS, Kasper CA, Tschon T, Emmenlauer M, Pique C, et al. ALPK1 controls TIFA/TRAF6-dependent innate immunity against heptose-1, 7-bisphosphate of gram-negative bacteria. PLoS Pathog. 2017;13:e1006224.

99. Ryzhakov G, West NR, Franchini F, Clare S, llott NE, Sansom SN, et al. Alpha kinase 1 controls intestinal inflammation by suppressing the IL-12/Th1 axis. Nat Commun. 2018;9:3797.

100. Miller MM, Taylor RL Jr. Brief review of the chicken major histocompatibility complex: the genes, their distribution on chromosome 16, and their contributions to disease resistance. Poult Sci. 2016;95:375-92.

101. Wise D. Understanding antigen processing in chickens using genome editing technology. Cambridge: PhD thesis, University of Cambridge; 2019

102. Trowsdale J, Knight JC. Major histocompatibility complex genomics and human disease. Annu Rev Genomics Hum Genet. 2013;14:301-23.

103. Fulton JE, McCarron AM, Lund AR, Pinegar KN, Wolc A, Chazara O, et al. A high-density SNP panel reveals extensive diversity, frequent recombination and multiple recombination hotspots within the chicken major histocompatibility complex B region between BG2 and CD1A1. Genet Sel Evol. 2016:48:1.
104. Potts ND, Bichet C, Merat L, Guitton E, Krupa AP, Burke TA, et al. Development and optimization of a hybridization technique to type the classical class I and class II B genes of the chicken MHC. Immunogenetics. 2019;71:647-63.

105. Gao C, Han LX, Qu LD, Luo YZ, Han JL. Specific TaqMan probed real-time quantitative RT-PCR methods and their application to differentiate the transcripts of duplicated BF or BLB genes in chicken MHC. Vet Immunol Immunopathol. 2012;145:590-6.

106. Schou TW, Labouriau R, Permin A, Christensen JP, Sørensen P, Cu H, et al. MHC haplotype and susceptibility to experimental infections (Salmonella Enteritidis, Pasteurella multocida or Ascaridia galli) in a commercial and an indigenous chicken breed. Vet Immunol Immunopathol. 2010;135:52-63.

107. Kinoshita K, Suzuki T, Koike M, Nishida C, Koike A, Nunome M, et al. Combined deletions of $\mathrm{IH}$ and $\mathrm{NHEJ} 1$ cause chondrodystrophy and embryonic lethality in the Creeper chicken. Commun Biol. 2020;3:144

108. Li J. Gene mapping of morphological traits in chickens. PhD thesis, Virginia Tech; 2017.

109. Jin S, Zhu F, Wang Y, Yi G, Li J, Lian L, et al. Deletion of Indian hedgehog gene causes dominant semi-lethal Creeper trait in chicken. Sci Rep. 2016;6:30172.

110. Li Z, Zheng M, Abdalla BA, Zhang Z, Xu Z, Ye Q, et al. Genomewide association study of aggressive behaviour in chicken. Sci Rep. 2016:6:30981

111. Okur V, Watschinger K, Niyazov D, McCarrier J, Basel D, Hermann $M$, et al. Biallelic variants in AGMO with diminished enzyme activity are associated with a neurodevelopmental disorder. Hum Genet. 2019;138:1259-66.

112. Alrayes N, Mohamoud HSA, Ahmed S, Almramhi MM, Shuaib TM, Wang J, et al. The alkylglycerol monooxygenase (AGMO) gene previously involved in autism also causes a novel syndromic form of primary microcephaly in a consanguineous Saudi family. J Neurol Sci. 2016:363:240-4.

113. Luo W, Luo C, Wang M, Guo L, Chen X, Li Z, et al. Genome diversity of Chinese indigenous chicken and the selective signatures in Chinese gamecock chicken. Sci Rep. 2020;10:14532.

114. Chamero P, Katsoulidou V, Hendrix P, Bufe B, Roberts R, Matsunami $H$, et al. G protein G(alpha)o is essential for vomeronasal function and aggressive behavior in mice. Proc Natl Acad Sci USA. 2011:108:12898-903.

115. Guo X, Fang Q, Ma C, Zhou B, Wan Y, Jiang R. Whole-genome resequencing of Xishuangbanna fighting chicken to identify signatures of selection. Genet Sel Evol. 2016:48:62.

116. Ishikawa A, Piao YS, Miyashita A, Kuwano R, Onodera O, Ohtake H, et al. A mutant PSEN1 causes dementia with Lewy bodies and variant Alzheimer's disease. Ann Neurol. 2005;57:429-34.

117. Wysocki M, Preuss S, Stratz P, Bennewitz J. Investigating gene expression differences in two chicken groups with variable propensity to feather pecking. Anim Genet. 2013;44:773-7.

\section{Publisher's Note}

Springer Nature remains neutral with regard to jurisdictional claims in published maps and institutional affiliations.

Ready to submit your research? Choose BMC and benefit from:

- fast, convenient online submission

- thorough peer review by experienced researchers in your field

- rapid publication on acceptance

- support for research data, including large and complex data types

- gold Open Access which fosters wider collaboration and increased citations

- maximum visibility for your research: over 100M website views per year

At BMC, research is always in progress.

Learn more biomedcentral.com/submissions 